\title{
Creating community life among immigrant survivors of torture and their allies
}

\author{
Nancy Bothne, PhD*, Christopher B. Keys, PhD**
}

\begin{abstract}
This qualitative study describes how immigrant survivors of torture in the United States built relationships among each other to form a psychological sense of community. Eight men and seven women from 11 different countries were recruited through a torture treatment center and a survivor-led advocacy and support coalition. This qualitative study explored how participants described their experiences of community life. An advisory group that included torture survivors, torture treatment practitioners, abolition advocates and academic experts guided the study. Data was analyzed using inductive and phenomenological theories. The construct of psychological sense of community articulated by McMillan and Chavis ${ }^{1}$ provided the conceptual framework for the evaluation of how a psychological sense of community was developed. Torture survivors with their allies formed community boundaries based on a deep understanding of the impact of torture. The safety afforded through the community boundaries was reinforced by shared condemnation of torture in all circumstances. Within the security of the community's boundaries, members shared their experiences to enable
\end{abstract}

\footnotetext{
* ) The Chicago School of Professional Psychology

${ }^{\star \star}$ ) De Paul University, Illinois
}

Correspondence to: nbothne@thechicagoschool.edu their own and others' recovery from torture. As community members exchanged advice and support, survivors met one another's needs, providing physical and emotional relief from the effects of their torture. As individuals and a community, they influenced each other's identities as survivors rather than victims. Advocating for those who remained vulnerable to torture was important to their identification as survivors. Through these exchanges, community members influenced one another and developed trusting relationships and emotional bonds. This study illuminates how community life enabled survivors to contribute to, and benefit from, each other's journeys.

Keywords: survivor, refugee, torture, community recovery, psychological sense of community

\section{Introduction}

There are few studies about how community-based interventions may contribute to recovery from torture. ${ }^{2}$ The ways in which emotional connections with others contribute to healing following human rights traumas such as torture are also understudied. ${ }^{3}$ This article explores the psychological dimensions of community life reported by immigrant survivors of torture in the United States. This phenomenological study amplifies the voices of torture survivors to 
describe what and how they experience a psychological sense of community.

Torture is deliberately used to break down the connection between individuals and their communities. ${ }^{4}$ Survivors are often psychologically and physically isolated from community life, by their torture and by their need to flee to safety. Torture is used to create fear of those who have been tortured ${ }^{4}$ and the resulting fear isolates vulnerable individuals from family and community. Intentionally or not, communities may multiply the harmful effects of torture. ${ }^{5}$ Survivors of torture are thus isolated from and by communities.

Therapeutic interventions with torture survivors are only modestly effective in helping survivors heal. ${ }^{6}$ Increasingly, participation in community life is being recognized as an important strategy for recovery from torture. ${ }^{6}$ Through that participation, survivors can restore their ability to emotionally connect with others, to offer and receive resources. ${ }^{7}$ The acknowledgement of torture by others is also important, ${ }^{8}$ perhaps the most important strategy in a survivor's recovery. ${ }^{9}$ To be able to then work against torture with others may contribute to the recovery of a community as well as individuals within it. ${ }^{6,10}$

The psychological dimensions of community life can be examined through a well-relied upon construct developed by McMillan and Chavis. ${ }^{1}$ Their conceptualization of psychological sense of community includes four elements. First, a community membership is defined by boundaries that indicate who is in (and who is out). Second, through their participation in the community, individuals are able to exchange resources to fulfill each other's needs. Third, communities and their members influence and are influenced by one another. Fourth, the shared emotional connections of a community are strengthened through the social rituals and ways in which members bond with one another. For the purpose of this study, the usual sequencing of McMillian and Chavis' conceptual framework (requiring mutual influence prior to the fulfillment of needs) has reversed steps two and three to better reflect the experience of the torture survivors who took part in this study; torture survivors first offer and receive support in fulfilling their human needs.

A psychological sense of community can offer those who experience it many benefits. Among survivors of child family abuse, experiencing a strong sense of community has been associated with attributes of resilience and positive mental health. ${ }^{11}$ South African immigrants in Australia were able to reclaim a new and positive identity by claiming community identity with each other based on their formerly pejorative classification as "colored". ${ }^{12}$ A psychological sense of community is also related to political participation, ${ }^{13}$ suggesting that community participation can lead to greater individual and community empowerment.

The construct of a psychological sense of community has been criticized for mythicizing homogeneity in a community, for failing to understand the ethnic, racial, national and cultural diversity that may contribute to and also challenge a psychological sense of community. ${ }^{14}$ The focus on individual rather than community benefit is also a critique of a psychological sense of community. ${ }^{15}$ This study can contribute to the body of research that examines the complexities of a psychological sense of community. By exploring how multinational, multiracial survivors of torture develop a psychological sense of community, this study may also deepen our understanding of a psychological sense of community among those whose shared emotional connections stem from their 
common experience rather than a common identity based on ethnicity, race, nationality and/or culture.

\section{Rationale and methodology}

This is a qualitative study, using a phenomenological approach to understand the lived experience of community life as experienced by immigrant survivors of torture in the United States. A qualitative study such as this is designed to provide deep understanding of the lived experience of community life as experienced by immigrant survivors of torture among each other. Consistent with a phenomenological approach, this study relies on survivors' own words to describe how and what they experience among each other.

\section{Community Partners}

The participants for this study were recruited through two programs that offer advocacy and support services for survivors of torture. The Torture Abolition and Survivor Support Coalition, International (TASSC) was founded in 1998 and is based in Washington, D.C. This survivor-led organization educates policy makers and the public on the ill-effects of torture. TASSC also works to meet the basic human needs of those who have been tortured by offering legal, medical, housing, food and employment assistance. TASSC meets regularly throughout the year, and offers special programs celebrating notable occasions. A significant program of TASSC is its "Communities of Healing" gatherings of torture survivors where they share their stories. Communities of Healing are designed to facilitate individual and community healing and empowerment. Communities of Healing are an important aspect of TASSC's week-long activities that recognize June 26 as the International Day in Support of Victims of Torture.

The Heartland Alliance Marjorie Kovler
Center also assisted with the recruitment of survivors. The Marjorie Kovler Center offers medical, mental health and social services. The center also engages in advocacy to abolish torture. A program that illustrates the Kovler Center's community-based approach is its regularly scheduled Friday night cooking group. A guest survivor-chef develops the menu, along with the staff. Survivors, staff and volunteers work together to prepare, serve, eat and clean up after the meal. The Marjorie Kovler Center, like TASSC, seeks to build a sense of community among torture survivors.

\section{Participants}

Eight men and seven women were interviewed for this study. They ranged in age from 27 to 60. Participants were from Albania, Angola, Cameroon, Chile, Congo, Eritrea, Gabon, Guatemala, Philippines, Rwanda and Uganda. Survivors of torture are identified by pseudonyms to humanize the participating survivors of torture and to maintain confidentiality.

In Chicago, participants were recruited through a modified snowball method, and recruitment efforts were conducted with the Marjorie Kovler Center and the Chicago membership of TASSC. The Kovler Center sent a letter to all clients informing them about the study, providing contact information so that interested survivors might contact the first author directly. TASSC members also reached out to survivors they knew to offer this opportunity. Ten people were recruited from Chicago.

TASSC staff and volunteers in Washington, D.C. also reached out to people they knew who might be interested. TASSC was particularly successful in recruiting women for the study. Five people, all women, were recruited through TASSC's efforts in D.C. At the request of TASSC, the study was 
cross-cultural rather than focused on one nationality or ethnic group.

Those eligible to participate in this study were immigrant adult survivors of government- sponsored torture who currently live in the United States. The recruitment method minimized the risks of a recruitment strategy that sought specific information about the act of torture itself. Rather, recruitment strategies sought people who identified themselves sufficiently as torture survivors to respond to solicitations seeking them. Also, as part of the pre-interview preparation session, participants were told that the study was about survivors of state-sponsored torture and asked if they qualified.

Informed consent procedures and the study design were approved by the Institutional Review Board (IRB) of the Heartland Alliance for Human Needs and Human
Rights, the parent organization of the Marjorie Kovler Center and the IRB of DePaul University. The Torture Abolition Survivor and Support Coalition also reviewed the study proposal and offered a letter of support.

\section{Interview Protocol and Procedure}

Participants engaged in semi-structured interviews using a survey protocol with openended questions. Interviews generally took about an hour and half; they ranged from 45 minutes to four hours.

The first author conducted all interviews. Three interpreters were used for four interviews, each requiring interpretation in English and French. Two of the interpreters were recruited through Kovler and/or TASSC. A third interpreter was found through networking. All of the interpreters were coached on their ethical obligations for

Table 1: Interview guide

Can you tell me more about your own story? What led you to come to the United States?

When I use the word community, what does that mean to you?

Now that you are in the U.S., are there any communities that you feel you are connected to, or a member of?

-What are those communities? What about them is appealing to you?

-When you say that you feel like you are a part of community, what does that mean to you?

-What is it about these communities that lead you to think you would like to be part of them?

How important to you are the following elements of community life?

- Understanding the boundaries of who is included in the community?

- Being able to get your needs met? Being able to meet the needs of others?

- Being able to influence the community? Being influenced by the community?

- Emotional connections with other community members?

Are there U.S. communities you do not want to be part of? Which ones? What is it about these communities that lead you to not want to be part of them?

Has being part of a community or communities affected your process of healing? How so?

Has not being part of a community or communities affected your process of healing? How so? 
accuracy and confidentiality. After participants gave informed consent, they were provided with the opportunity to share their stories of coming to the United States.

In the interview, participants were asked to describe communities that were important to them in the United States. Specific questions about a psychological sense of community were also posed, e.g. "how important are emotional connections in community life?" Throughout the interviews, participants were encouraged to elaborate on elements of a psychological sense of community. They were also asked to indicate whether, and if so how, these elements applied to their own life circumstances. The questions that guide this article's analysis of the data are identified in Table 1.

\section{Community Consultation}

An advisory body including torture survivors, abolition activists, torture treatment professionals and academic advisors helped guide the research process and evaluate the results. The torture survivors were also members of TASSC. One person was recruited to facilitate the group; she also helped monitor the well-being of the participants during the meetings. In addition to the advisory body, the Marjorie Kovler Center and TASSC provided guidance. This community consultation process was essential in guiding the direction of the study, recruiting participants and developing protocols sensitive to the special needs of torture survivors. The advisory group was also very helpful in evaluating results to explore the depths of their meanings.

\section{Data Analysis}

A research team of undergraduate students was recruited and trained to assist with coding the data. Individual research team members initially engaged in open coding by reviewing interviews line by line to identify significant statements. The significant statements were clustered into major themes and categories. Agreement about the major themes and categories found within the data was then determined through group discussion. When disagreement about coding occurred, the team worked together to understand the meaning of the text within the context of the participant's overall interview. Using this technique, the team sought to code data to reflect the phenomenological meaning of community life as experienced by participants. A set of exhaustive codes was thus created.

Codes were not necessarily based on the questions themselves. Rather, the codes were developed from two foundations: categories of participant responses and those developed from theory. For example, participants began to make a distinction between communities into which they were born (such as extended family or ethnicity) from communities with which they associated by choice (such as their survivor group). This led to the creation of a code specifying whether the participants were 'born into' or had 'chosen association' with the community. Codes were also developed based on elements of psychological sense of community. ${ }^{1}$

Data could receive multiple major thematic codes. For example, one quote may be identified by location, the association the participant had with the community (born into it? affiliated by choice?), and the kind of community (political, neighborhood, etc.). All data was uniquely identified within each major theme, as set out in Table 2 .

Once a final coding scheme was agreed upon, research team members coded each 
Table 2: Coding Structure of Major Themes

1. Community location
a) in the United States
b) in country of origin
c) unspecified/ambiguous

2. Association with community
a) born into
b) chosen community

\section{Kind of community}
a) national identity (country affiliation)
b) immediate and extended family
c) ethnic but not extended family
d) religious
e) political, social justice or human rights oriented
f) recovery
g) neighborhood
h) gender-specific

4. Elements of a psychological sense of community
a) membership boundaries
b) mutual influence
c) meeting needs
d) emotional connections

transcript using Nvivo software. This software program made it possible to further explore relationships across coding structures, enriching the understanding of the data. For example, the software allowed separation of data by codes and themes between men and women, and the different kinds of communities in which survivors were involved in the United States e.g. religion-based or recovery-based.

The analysis was conducted using the scientific paradigm of constructivism-interpretivism. Constructivist-interpretivist methods recognize the interaction of the participant and researcher to make meaning of the data. ${ }^{17}$ Constructivist-interpretivist methods guide multiple facets of how research is conducted; they constitute a paradigm that also includes phenomenological theory. ${ }^{17}$ Consultations about the meaning of the data were held in Chicago and in Washington, D.C. with torture survivor groups throughout the research process. Consultations were also held with the research advisory body. These consultations helped strengthen the process used to interpret the data. Such consultations also ensured that the voices of survivors were integral to the study throughout its process.

The advisory body was particularly helpful in providing context. For example, a participant indicated to the first author that he rejected a psychological sense of community with his ethnic group located in Chicago. However, this participant was to be seen at multiple gatherings held by his nationally-based ethnic group. Working with the advisory group, we concluded that this participant was likely to enjoy the food, customs and language of other people from his country. He did not experience the close emotional bonds that characterize a strong psychological sense of community.

When there were disagreements or questions about the meaning of the data, the researcher consulted with her academic advisors and the advisory group. All disagreements were successfully resolved.

\section{Authors' Perspectives}

This study is based upon the master's thesis of the first author. The first author had over ten years of experience working with torture survivors through her prior staff role with Amnesty International USA. In that capacity, she worked together with torture survivors to abolish torture in the United States and countries throughout the world. This experience afforded her credibility with the community. Torture survivors want to know that those who work with them will also take action against torture. ${ }^{18}$ The first author also participated with TASSC International and the Marjorie Kovler Center to protest 
country policies that support torture and human rights abuses in demonstrations and other public events. Three participants indicated directly that they knew the first author through her prior staff role with Amnesty International. The second author supported the first author's stance regarding torture and hearing the perspectives of all advisory group members. He was not known for participating directly in human rights activism.

\section{Results}

The ways in which a psychological sense of community was experienced among immigrant survivors of torture who participated in this study is captured through the four constructs developed by McMillan and Chavis: ${ }^{1}$ membership boundaries, needs fulfillment, mutual influence and emotional bonds. Participants described their community relationships as experienced through the Marjorie Kovler Center and TASSC International. Both TASSC and Kovler provided safe space for those who had been tortured. Table 3 provides a summary of how participants described the psychological sense of community found among one another.

Table 3: Summary of the application of McMillan and Chavis' Elements of a Psychological Sense of Community as Experienced by Immigrant Survivors of Torture

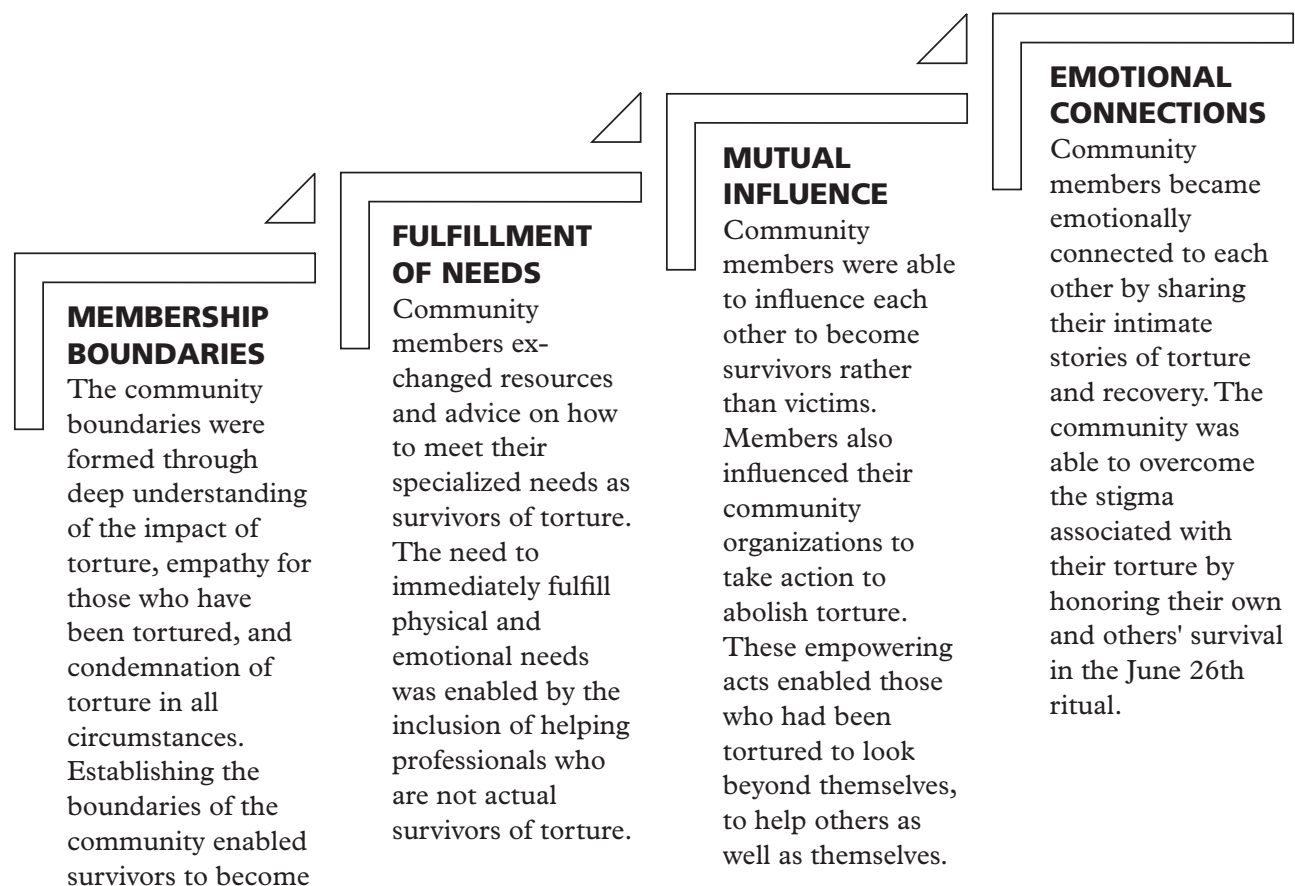




\section{Membership Boundaries}

Membership boundaries define who is in the community. They also define who is not, who is excluded. ${ }^{1}$ The participants in this study defined the boundaries of their community as wide enough to embrace the diversity of their backgrounds. Fundamental to the shared bonds of community life was the unequivocal condemnation of torture.

Participants described a survivor community that was open and willing to include diverse peoples. Kharen wanted to become a member of TASSC to join "an international community of people who went through the same experience." Marcelo described a mural at the Kovler Center that represented the survivor group: "It's beautiful to see people from so many different countries, different cultures.... It's beautiful to see." Survivors' appreciation of diversity implicitly acknowledged everyone's vulnerability to torture, no matter what country they were from. When this study began, TASSC asked that participants be included from many countries and diverse cultures. This was important to them in order to underscore how widespread torture is, and how similar the experiences of recovery are.

The psychological sense of community experienced by this multinational group contrasts with the experience of Evrard. Evrard specifically rejected any emotional affiliation with people from his own country living in the United States. He explained that he could not share his experiences with people from his country, because of the condemnation and stigma associated with his torture and that of his daughter. Here in the United States, he said, “I don't feel free to go there, and I never go there. We have a Congolese community; I never go there."

Included within the community of this multinational group were those allies and program staff who had not been tortured. Membership boundaries also embraced those who chose to empathize with those who have survived torture. The relative safety experienced within the community was not dependent upon members being survivors. Community events such as cooking nights or U.S. holiday celebrations included family members, volunteers, torture abolition advocates, and other supporters of TASSC and Kovler. Kharen said, "I don't want it (the survivor community) to be an exclusive club for survivors. They could be fans of survivors who are empathizing.... You know, the fact that they put their shoes in that person [walked in that person's shoes] is really something good." Francie explained, "If we open the doors just for survivors, how are [other] people going to know the difficulty of torture?"

Membership boundaries thereby included those who deeply understood and consequently condemned torture. Okello described explicitly how important it was that torture be condemned. He said that "people ... who have not seen torture have found ways of justifying it." Okello explained how important it was that in TASSC he met "people whose commitment against torture knows no boundaries." Community members were bound by their common condemnation of torture, under all circumstances.

The setting in which survivors met also helped define community boundaries. "When you meet me here at Kovler (where our interview took place), that means I am part of the Kovler community," stated Japhet when asked if he considered himself a part of the Chicago survivor community. In one case, a participant had not been in the center for a few months. He was greeted by survivors and staff as an old friend; he was reconnected with his survivor community. The setting created a space in which 
survivors of torture could be recognized as individuals.

The boundaries of the community were formed by a shared understanding and condemnation of torture. That understanding of torture offered relative safety within which community members could overcome national and cultural differences. In settings offered by treatment programs, survivors could be free from the challenges of negotiating relationships with people who might not condemn their having been tortured.

\section{Needs Fulfilment}

The integration and fulfillment of needs is a system of sharing and reinforcement that benefits members of a community. ${ }^{1}$ Survivors shared useful tips that helped fulfill their basic human needs, for things such as housing and travel tips, as well as techniques to help sleep and heal. As survivors revealed their helpful hints, they began to overcome the isolation that resulted from their torture. Among each other, survivors began the basic steps needed to connect to others.

The staff of Kovler and TASSC were important resources for fulfilling the needs of members of the community. In comparing the assistance he has received from non-survivor communities, Okello said, "There are lots of communities that go out of their way to help people...." He added that unlike the staff at Kovler, "they don't know how to do it.” Joelle also appreciated Kovler staff for their help in meeting both practical and personal needs: "They will refer me to counselors; they will refer me to hospitals. They will refer me to some other small human rights groups where I will go and get food." She also found it valuable that "they will take time to mix a cup of tea and serve me with it because they want me to feel good, just because they want to console me. .... Everything that will make my life comfortable."
Within TASSC and Kovler, survivors offered useful tips on how to survive and recover from the harsh after-effects of torture. Francie said, "If I have difficulty to sleep.... People from TASSC can give you some advice." Francie went on to mime how she was advised to "close the door like that" so that it was partially open and allowed some light into the room. "It (TASSC) has helped me heal," said Felizardo. "It's still very painful for me, but little by little I am not crying anymore." Through their understanding of each other's needs, participants were able to offer practical tips that reflect their understanding of the particular effects that torture has had.

Survivors offer strength-based strategies to help meet each other's needs. They listen to explanations of what happened to others and the many negative effects that followed. Angelique described how helpful it was to talk to those who have gone through torture and other human rights trauma, and who have moved on to build a future. "It's like they comfort you to be strong, to be fine, you'll be fine, you'll be fine... They can talk to you.... It happened in different countries; we talk and it helps." Angelique was able to benefit from the stories of those who survived before her, whose tips allowed her to envision a future where she would be fine.

Physical, psychological and emotional needs were met among the members of the community. Torture survivors were able to recognize each other's needs and to identify specific strategies to ameliorate the pain others were feeling. With assistance from caring staff, survivors could begin to heal.

\section{Mutual Influence}

The exchange of influence between the whole community and its individual members, and among individual members is important in building a foundation from 
which nurturing relationships can develop. ${ }^{1}$ The way in which influence was exercised through the community and its members strengthened their individual and communal capacity to resist torture and promote healing beyond their physical needs.

It is important for survivors to influence and thereby help other survivors. Joelle said of influencing others' recovery: "It is very, very, very important to me because ... It helps me change part of their darkness to light." Joelle explains the psychological benefit to herself by adding that helping others by influencing their healing "makes me fulfill my heart's desires."

Angelique described how TASSC members influenced her recovery. "They say 'you been through that?' and 'you helped me; I saw you as strong." The mantle of victimhood has been imposed on them by perpetrators. To have their stories of torture interpreted as strength is a power shared among community members. The rejection of the victim label and the commitment to move beyond the powerlessness it suggests demonstrates how the community they formed influenced survivors' healing. These survivors created the sense of community that enabled their mutual survival from torture.

Throughout these interviews, participants described how difficult healing from torture is. Nonetheless, participants also described their strong identification as survivors of the cruelty of torture. Rodrigo described how he was able to become a survivor rather than a victim and how that enabled his emotional recovery. He said, "Victim to me is a concept that you stay there. You are not able to heal and go far beyond being a victim...." At Kovler with other survivors, he explained, we "discuss with people about the concept of survivors and victims." He described how important the difference was, "because survivors can act, survivors can denounce... we let people know what happened." As individuals adopted the identity of survivor, they identified more strongly with the community. This identification was also reinforced by the names of the community partners: the Marjorie Kovler Center for Survivors of Torture and Torture Abolition and Survivors' Support Coalition.

Several participants expressed how important it was to them that TASSC and its members influence policies that affect those who remain vulnerable to torture. Simon said, for example, "What I expect from an association like TASSC is basically to write to the United Nations or do something about it (torture) so that it doesn't happen again." Simon expected TASSC to encourage and influence TASSC members to engage the United States government in condemning torture. Joelle also described how important it was to her that TASSC "sent me to the radio for some interviews." For her, a main purpose of TASSC is to work with her community to change public policy and perceptions that condone torture. Joelle continued, "We've been to the Congress. We went round [to] the Congress members appealing to them for certain laws [regarding torture] not to be like this or to be like that."

As survivors began to share the useful tips that enabled each other's healing, they began to influence each other and the community as a whole. It was important to influence each other's strengths, to emphasize their survival. As survivors brought together because of their torture, it was also important for them to exercise their community influence on Congress so that torture may one day be eliminated.

\section{Emotional Connections}

Emotional connections are often based on a shared history and the extent to which 
members invest in the community. Building relationships within a community, exchanging advice with others and, in the process of doing so, meeting emotional and physical needs, and positively influencing one another's recovery may foster strong emotional bonds. ${ }^{1}$ The emotional connections among community members may also be formed as a defense against those who may condemn, be fearful of, or stigmatize those who have been tortured.

Sharing stories about how one has been tortured created intimacy. Rodrigo described his reluctance to share his story of the pain caused by torture. Within the survivor community, Rodrigo described how "it is easier to connect to them, to survivors. There is another degree, another emotional connection that goes deeper."

Survivors shared more than advice, they shared a common vulnerability. As survivors told their stories and bore their vulnerability, they were able to more intimately connect with each other. It was at a TASSC meeting, Evrard said, where he was first able to speak of the rape of a family member. He said that TASSC and Kovler are "two communities that know about what I am, what I am in my country. What is my daughter, what is my wife, what is my kids. It is TASSC and Kovler who knows it." For Rodrigo, Evrard and other survivors of torture, sharing their stories created an intimacy that strengthened their relationships to each other.

The emotional bonds experienced by survivors were often likened to those experienced within a family. Francie described her feelings about TASSC as more than family. Francie offered that, "Family, like my husband or my kids, is something God has given you, but the community like TASSC is family with the heart. TASSC is from the soul." Kiki also likened her appreciation to TASSC to that of family: "I feel like I have family here in America because I have TASSC." Claire said, "In your mind you know that you have a person who will take care of you, take care for you." Marcello described how "you feel that you are loved, that you don't feel isolated and that you don't feel lonely." Summing up how important his emotional bonds are to the community, Japhet said, "Even if you were to separate yourself from the community, there would still be parts of the community that would stay with me. Even if you leave, there are things that would make you come back."

The emotional bonds experienced among survivors are recognized through rituals and celebrations like the United Nations International Day in Support of Victims of Torture. The June 26 events of the International Day in Support of Victims of Torture provided opportunities to honor survival from torture. Felizardo explained, "I'm connected to the Kovler Center because every 26 of June, every year, they have celebration of international survivors." This event is the opportunity to share joy in each other's company, to speak openly about torture in a world where others are not interested in it. Remembrance is of those not present and those who can be celebrated at TASSC and Kovler June 26 events. Another TASSC member said that June 26 is "where we embrace our spirit and each other... it is rebirth."

The experience of torture results in severe physical and psychological trauma, undermines the capacity to build trusting relationships with others, and often leads to feelings of isolation and withdrawal from others. Survivors able to build a psychological sense of community with each other may be able to rely on those community bonds to help transform themselves from victim to survivor. The term of survivor versus victim becomes a symbol of individual and commu- 
nity empowerment and connectedness. Survivors of torture built strong emotional connections that enabled their healing.

\section{Discussion}

The concept of a psychological sense of community ${ }^{1}$ provides a tool that enables an intimate examination of survivors' relationships with each other. This study identifies how torture survivors can rebuild emotional connections to others and, in doing so, begin to heal themselves and others. In this study, recovery from torture involves more than reducing symptoms of Post Traumatic Disorder Syndrome (PTSD). Rather, this study examines how survivors can begin to enable each other to recover a health that includes physical, mental and social wellbeing. ${ }^{19}$

The full recovery from torture involves both relieving PTSD symptoms ${ }^{10}$ and building the capacity to experience emotional connections with others. ${ }^{4}$ Those who participated in this study were a diverse group of people who had been significantly wounded by torture. Unable to fully engage with people from their own countries because of concerns that echoed the divisions they fled, survivors of torture engaged with those who understood their experience. Social support of each other enables a community to define the meaning of their trauma. ${ }^{22}$ The survivors interviewed for this study were able to redefine their trauma as a resource. Through shared disclosures and helpful hints on what to do to heal, survivors were able to recognize each other as healers, as experts on how to recover from torture.

Survivors must believe that the support from others will result in real changes to their lives in order for that support to be most effective. ${ }^{18}$ Sharing their healing experiences through their community lives enabled survivors to believe in other survivors, and believe in themselves. Among torture survivors, those values included a reliance on strength-based approaches, condemnation of torture, and a commitment to share healing strategies.

It was through these exchanges that the community developed social capital, the resources that individuals and the collective could rely on to negotiate their stress. High social capital, having access to available resources that meet human needs, has only recently been linked to a decrease in individual experiences of posttraumatic stress. ${ }^{20}$ It is not just the helpful treatment that survivors receive from torture treatment programs that enable their healing. Survivors help each other on their journeys of healing by internalizing the group norms, declaring themselves as survivors. It is not the label, per se, that empowers individuals. Rather, survivors can heal by believing in their own power to act, to denounce what happened to them.

The participants in this study demonstrated how important it was to their sense of community to think of those beyond themselves who remained vulnerable to torture. Indeed, June 26 events offer this opportunity every year. The participants in this study relied on their relationships with each other to transform how they understood their torture.

McMillan and Chavis ${ }^{1}$ describe the influence of the community on individuals and individuals on the community as an exchange of power. The exchange of power described by participants in this study resulted in individual and community identification as survivors rather than victims of torture. This concept of being survivors was described as one that provided empowerment, allowing survivors to act and denounce torture. Empowerment is an 
important strategy in torture healing. ${ }^{18}$ Although it is individual empowerment that is most often discussed, participants in this study represent how important it is to also act as an empowered community. ${ }^{21}$ The social transformation of their trauma has the potential to transform society's views of torture as well. ${ }^{22}$ Like Mothers Against Drunk Driving, the community created by torture survivors can use their personal experiences to educate and try to influence U.S. policy. ${ }^{22}$

\section{Torture Treatment}

The exploration of community-based strategies for recovery from torture is underexplored. ${ }^{8}$ Yet the importance of relationship-building as a recovery strategy is emphasized in many torture treatment programs. ${ }^{15}$ Participants described their reluctance to share their stories with members of the family into which they were born. Many described the rich connections made with other survivors as the bonds that constituted their family now. Enabling the development of emotional vulnerability among torture survivors may be an important strategy in order to heal following torture - and one available primarily, if not only, within the context of other survivors and their allies.

Research about social identification and community indicates that a psychological sense of community is stronger among those individuals who choose to form communities based on shared interests and social identification rather than geography. ${ }^{23}$ When individuals who have been tortured self-represent as survivors, they may be indicating their openness to building relationships with other people. Those who have been tortured benefit from the specialized services and opportunities to meet others similar to themselves that torture treatment programs offer.
Understanding how community life can flourish among those who have been tortured begins to build a foundation for further development of community-based strategies that enable torture survivors to heal. This study offers insight into how healing can progress based on the interactions of individuals and communities. Whether survivors can use the positive psychological sense of community they experience among each other to then reach out to other communities is yet to be studied. One strategy for providing opportunities for individuals to develop their capacity for emotional and social well-being is through collective exchange in a safe and understanding place. The impact of torture is profoundly felt at individual and community levels. So, too, is the recovery from torture.

\section{Limitations}

This study examined the community life found among immigrant survivors of torture who participate in the Marjorie Kovler Center for the Treatment of Survivors of Torture and in Torture Abolition and Survivors Support Coalition (TASSC) International, and who agreed to participate in this study. Both of these programs utilized community-based methods to work with those who have been tortured. Those survivors who agreed to be interviewed were self-selected; that may reflect the biases of individuals who are more likely to engage with others and consequently to engage in communities.

Likewise, the first author of this study was known by at least three of the Chicagobased participants as an activist working against torture. Some participants may have tried to relate to the author by sharing stories of activism and opposition to torture. Engaging with the advisory group to probe the meaning of participants' responses was 
useful to probe beyond the author's experience and understanding.

Notwithstanding these potential limitations, study participants revealed much about their understanding of what it means to be part of a community of survivors. Although qualitative research is not generalizable, it does provide rich insights into how life is lived. This study captures the voices of the participants who shared their ideas of a psychological sense of community. Rather than speaking for all survivors, the participants disclose the depth of their experiences. They help us develop an initial understanding of how a psychological sense of community may be built among immigrant survivors of torture in the U.S.

Other limitations may have occurred as a result of the cultural, language and gender differences among the participants, interpreters and the researcher. Exacerbating such differences was the emotional nature of participants' experiences and the emotional reactions that occurred in response to them. There is no clear formula for negotiating such complexity and thus the potential for error. At the same time, however, the richness of the experience of a psychological sense of community amidst such diversity could only have been captured by engaging, not avoiding, such diversity. Indeed, a phenomenological method is recommended for capturing the essence of the lived experience, in all its diversity. The thoughtful exchange with the survivors, torture treatment professionals, torture abolition advocates and academic experts that participated in the community consultation group was helpful.

Since 1986, the McMillan and Chavis ${ }^{1}$ construct of a psychological sense of community has been relied upon to examine the psychological connections of individuals within a community. This framework has been criticized for some shortcomings, including failing to recognize a collective (rather than individual) obligation to the community ${ }^{15}$ and for neglecting to attend to diversity within communities. ${ }^{14}$ It is nevertheless a foundational theory that continues to be useful to community psychologists around the world.

\section{Conclusion}

Survivors of torture face many challenges as they seek to recover from torture and rebuild emotional connections with others. Participants in this study sought community life with survivors of torture from any country and any culture. The diversity they represent challenges a commonly held view of community life as homogeneous and static. $^{14}$

The psychological sense of community participants built among each other required that each community member condemn torture unequivocally. They offered and received useful tips to enable each of them to heal and recover from their torture. As individuals and a community, they sought to influence each other's journey of healing by laying claim to their identities as empowered survivors. Finding safety in accepting each other, meeting one another's needs, influencing each other to foster healing and ultimately sharing and supporting one another's vulnerabilities built strong emotional bonds among survivors and allies in this community. This study offers an examination of how important it is for those who have been tortured to build a psychological sense of community within which they can experience healing and emotional connectedness. 


\section{Acknowledgements}

Many survivors of torture offered their stories of healing as contributions to the well-being of others who share experiences of torture. These survivors of torture offer inspiration for understanding healing and humanity. The Heartland Alliance's Marjorie Kovler Center for the Treatment of Survivors of Torture and Torture Abolition and Survivors Support Coalition (TASSC) International both provided ongoing support for this study. We appreciated their guidance, input, support and camaraderie on this journey.
References

1. McMillan DW, Chavis DM. Sense of community: A definition and theory. J Community Psychol. 1986;14(1):6-23.

2. McFarlane CA, Kaplan, I. Evidence-based psychological interventions for adult survivors of torture and trauma: A 30-year review. Transcult Psychiatry. 2012 Jul;49(3-4):539-67.

3. Hutchinson E, Bleiker, R. Emotional reconciliation. Reconstituting identity and community after trauma. EJST. 2008 Aug;11(3):385-403.

4. Gonsalves C J, Torres T A., Fischman Y, Ross J, Vargas, M O. The theory of torture and the treatment of its survivors: An intervention model. J Trauma Stress. 1993 Jul;6, 351-365

5. Anckerman S, Dominguez M, Soto N, Kiaerulf F, Berliner P, Namia Mikkelsen E. Psycho-social support to large numbers of traumatized people in post-conflict societies: An approach to community development in Guatemala. J Community Appl Soc Psychol. 2005 Mar;15(2):136-152.

6. Ginzburg K, Neria Y. Mental health interventions for survivors of torture: Current status and future directions. Z Psychol [Internet]. 2011;219(3):187-189. DOI: 10.1027/2151-2604/ a000068

7. Berliner P, Mikkelsen, EN. Psycho-education with asylum seekers and survivors of torture. Int J Adv Couns. 2006 Sep;28(3):289 -301.

8. Lueger-Schuster, B. Supporting interventions after exposure to torture. Torture. 2010;20(1):3244.

9. Rauchfuss K, Schmolze, B. Justice heals: The impact of impunity and the fight against it on the recovery of human rights violations' survivors. Torture. 2008;18(1):38-50.

10. Kira IA, Ahmed A, Mahmoud V, Wassim F. Group therapy model for refugee and torture survivors. Torture. 2010;20(2):108-13.

11. Greenfield EA, Marks NF. Sense of community as a protective factor against long-term psychological effects of childhood violence. Soc Serv Rev. 2010 Mar 1;84(1):129-147.

12. Sonn CC, Fisher AT. Psychological sense of community in a politically constructed group. J Community Psychol. 1996 Oct;24(4):417-430.

13. Davidson WB, Cotte PR. Sense of community and political participation. J Community Psychol. 1986; 17(2):119-125.

14. Wiesenfeld E. The concept of "we": A community social psychology myth? J Community Psychol. 1996 Oct;24(4):337-346.

15. Nowell B, Boyd N. Viewing community as responsibility as well as resource: Deconstructing the theoretical roots of psychological sense 
of community. J Community Psychol. 2010 Sep;38(7):828-84.

16. Strauss A, Corbin, J. Basics of qualitative research: Techniques and procedures for developing grounded theory. Thousand Oaks, CA: Sage Publications; 1998.

17. Ponterotto JG. Qualitative research in counseling psychology: A primer on research paradigms and philosophy of science. J Couns Psychol. 2005 Apr;52(2):126-136.

18. Fabri M, Joyce M, Black, M, Gonzalez, M. Caring for torture survivors: The Marjorie Kovler Center. In: C Stout, editor. The New Humanitarians: Inspiration, Innovations, and Blueprints for Visionaries. Westport, Connecticut, London: Praeger; 2009.

19. World Health Organization. Mental health: A state of well-being [Internet]. 2014. [updated August 2014]. Available from: http://www.who.int/ features/factfiles/mental_health/en/.

20. Wind TR, Komproe IH. The mechanisms that associate community social capital with postdisaster mental health: A multilevel model. Soc Sci Med. 2012 Nov;75(9):1715-20.

21. Keys C, McConnell E, Motley D, Liao L, McAuliff $\mathrm{K}$. The what, the how and the when of empowerment: Reflections on an intellectual history. In Bond M, Serrano-García I, Keys C, editors. Handbook of Community Psychology. Washington DC: American Psychological Association. Forthcoming 2017.

22. Bloom S L. By the crowd they have been broken, by the crowd they shall be healed: The social transformation of trauma. In Tedeschi R, Park C, Calhoun L, editors. Post-Traumatic Growth: Theory and Research on Change in the Aftermath of Crises. Mahwah, NJ: Lawrence Erlbaum; 1998.

23. Obst P, White K. Choosing to belong: The influence of choice on social identification and psychological sense of community. J Community Psychol. 2007 Jan;35(1):77-90. 